S sciendo

\title{
Belief and Normativity
}

\author{
Pascal Engel \\ University of Geneva \\ Disputatio Vol. 2, No. 23 \\ November 2007
}

DOI: $10.2478 /$ disp-2007-0009

ISSN: 0873-626X 


\title{
Belief and normativity
}

\author{
Pascal Engel \\ University of Geneva
}

\begin{abstract}
The thesis that mental content is normative is ambiguous and has many forms. This article deals only with the thesis that normativity is connected to our mental attitudes rather than with the content of the attitudes, and more specifically with the view that it is connected to belief. A number of writers have proposed various versions of a 'norm of truth' attached to belief. I examine various versions of this claim, and defend it against recent criticisms according to which this norm lacks normative force, that it violates the principle that 'ought implies can,' and that it is viciously circular. I defend the view that we should distinguish the statement of the objective norm and the way it is regulated, and that this distinction can answer most of the criticisms of the norm of truth for belief.
\end{abstract}

\section{Introduction: issues about normativity}

It seems to be a platitude that belief is governed by a norm of truth. Is not the point of belief to believe truths? Is not it a requirement of believing that we should not believe falsehoods? A number of philosophers, however, deny this. Although they recognise that there is an intimate connection between belief and truth, they reject the idea that this connection is normative. Indeed, they tell us, beliefs 'aim' at truth in the sense that to believe that $\mathrm{P}$ is to believe that $\mathrm{P}$ is true, or in the sense that it is the 'direction of fit' for beliefs that they should adapt to the world, but there is no more in this than a trivial fact about belief as a propositional attitude. To elevate this trivial fact to the status of a 'norm' is to transform an innocent platitude into a pompous falsehood. For there is nothing normative about believing: neither we believe with an eye fixed on the horizon of an ideal of truth nor we obey any prescription to believe the truth. On the contrary, we believe all sorts of things, some rational, some irrational, some justified, some unjustified, some true, some false, and there is no particular norm that we follow, no particular prescription that we obey and no particular sanction that we incur when we go off

Disputatio, Vol. II, No. 23, November 2007 (special issue) 
track. Believing is just a natural mental state, which has certain causes and certain effects, and which answers no particular rational or normative essence. These reactions to the thesis that belief is governed by a norm of truth seem to bear the seal of common sense.

Nevertheless, the thesis that belief carries or involves a normative dimension, which is intrinsically connected to truth, seems to me both true and important. It is important for the philosophy of mind, since it is part of what makes belief specific among other attitudes and is connected to the impossibility of believing at will; for epistemology since it helps us to understand the role of belief in an analysis of knowledge; and for the philosophy of normativity since it helps us to understand the vexed question of whether there is a normative dimension, and which one, in mental content. But this thesis is not true without qualifications, and it has several versions, depending on how one understands the normative involvement.

Before trying to assess the issue of the normativity of belief, it is important to draw a rough - and necessarily incomplete - map of the general questions which arise about the notion of normativity. When one talks about norms, there are several strands. In the first place, 'norm' and 'normative' belong to a family of notions which are often not distinguished easily. In particular, are norms the same thing as rules? If norms carry a dimension of evaluation, how does one distinguish them from values? Should they be expressed in terms of deontic concepts, such as those of obligation or permission? Do all norms trade into oughts and shoulds? What is their domain of application? No one contests that there are moral norms, social norms, and aesthetic norms. But are there norms for beliefs and for mental contents? Are there epistemic norms in addition to practical and aesthetic ones? All of these issues are moot, and the concept of norm is, in many respects, a vague one. I shall not try to settle them here. Three kinds of questions, however, are prominent:

a) Semantical: How should we formulate the norm for belief? It is generally agreed that the normative dimension in belief is its dimension of correctness, and that the norm for belief, if there is such a norm, is that a belief is correct if and only if it is true. But what is the relationship between this correctness condition and its application to particular beliefs? In particular, does it entail special prescriptions in the form of statements about one ought to believe? 
b) Epistemological: Given that there are specific norms for belief, how do we come to know them? How are they used when we attempt to conform to the norm? It seems to be a requirement on any norm that someone who is subject to it has to know how to conform to it. It is also an apparent requirement that if one is subject to a normative requirement one is at least able to conform to it, and to see how one can do so (ought implies can). In other words, how does the norm regulate the behaviour of the agents or subjects which are supposed to be subject to it? I group all such questions under the epistemological heading

c) Ontological: are the norms of belief real properties of belief? If so, are they essential or derivative? In general, there are two positions relative to the ontology of moral norms in meta-ethics: one can be a cognitivist about them, and take them as objective, or one can be a non-cognitivist or an expressivist, and take them as mere expression of our psychological attitudes. Is there a parallel opposition about epistemic norms and norms of thought? There is no reason to think that there is not.

Here I shall deal mostly with the semantical and epistemological issues, and shall leave aside the ontological ones.

Several kinds of epistemic norms are said to govern belief: truth (a belief is correct if it is true), evidence (a belief is correct if it rests upon sufficient evidence), knowledge (a belief is correct if and only if it aims at knowledge), rational norms (a belief is correct if and only if it is rational). A full account of the norms for belief would need to consider all these, and would have to analyse their relations. It would also have to determine whether there is a hierarchy among these norms, and whether one of them is candidate for being more fundamental than the others are. Similar issues arise about assertion, which are, in many respects, close to those about belief, and it is interesting to consider these similarities and differences. But here I shall abstract from all these issues, and consider only the proposal that there is a basic norm for belief, namely truth. My main question is not whether truth, or another norm, is the fundamental norm for belief. It is rather this: in so far as we admit that truth is the fundamental norm for belief, in what sense is it normative? My objective here is to try to assess various versions of the view that truth is the norm for belief, to clarify them and to explain which version is, in my view, the most credible. In doing so, I shall try to answer some criticisms of the normativity of belief thesis, which have been voiced recently, in particular, by Kathrin 
Glüer and Åsa Wikforss (forthcoming), Asbjörn Steglich-Petersen (2006), and Bykvist and Hattiangadi (2007).

\section{How to formulate the truth norm?}

The idea that there are conditions under which a belief is correct seems to be the most general way for characterising the normative dimension of belief. For instance, Alan Gibbard says:

'For belief, correctness is truth. Correct belief is true belief. My belief that snow is white is correct just in case the belief is true, just in case snow is white. Correctness, now, seems normative ... The correct belief, if all this is right, seems to be the one [a subject] ought, in this sense, to have.' (Gibbard 2005: 338-39)

From this we can derive a formulation of the norm of truth for belief:

(NT1) For any $\mathrm{P}$, a belief that $\mathrm{P}$ is correct iff $\mathrm{P}$ is true.

and if we express the notion of correctness in prescriptive terms:

(NT 2) For any $\mathrm{P}$, one ought to believe that $\mathrm{P}$ iff $\mathrm{P}$.

which is the one favoured by various writers would have defended what I shall call the normative account (Wedgwood 2002, Boghossian 2003, Engel 2002, Shah 2003).

A different formulation is James' famous declaration:

'There are two ways of looking at our duty in the matter of opinions ways entirely different, and yet ways about whose difference the theory of knowledge seems hitherto to have shown very little concern. We must know the truth; and we must avoid error — these are our first and great commandments as would-be-knowers; but they are not two ways of stating an identical commandment, they are separable laws.' (James 1896)

James' statement occurs within the context of his famous analysis of the will to believe and of the ethics of belief. James expresses himself in deontic terms - he talks about duties, commandments, and 'musts,' but elsewhere in his article he makes it clear that he is not simply talking of duties, but also of epistemic aims and interests, and 
of epistemic values in general. ${ }^{1}$ If we express the relation between truth and belief in terms of interests, it is natural to express the relevant notion of correctness in terms of our desire about our true belief. The 'norm' for belief simply becomes

(DES) We desire that we believe that $\mathrm{P}$ if and only if $\mathrm{P}$ is true (Piller 2006).

Of course, the desire in question is not simply a contingent and transient desire, but a second-order belief to have certain desires. From this formulation it is easy to move to a formulation in terms of value (given the dispositional theory of value which derives values from desires about desires):

(VAL) We value that we believe that $\mathrm{P}$ if and only if $\mathrm{P}$.

Before trying to assess these formulations, we need to understand what the status of a norm of truth for belief is. Is it a requirement on belief as a mental state? Is it a property of the contents of our beliefs, i.e. of their propositional content? Or is it a property of our beliefs within the general context of inquiry? The question becomes particularly pressing if we consider the norm for belief in relation to other norms which are said to govern belief. Beliefs are not subject simply to a truth norm, but also to rationality norms. In general,

(NR1) For any $\mathrm{P}$, a belief that $\mathrm{P}$ is correct iff it is rational.

Which we can express as a prescriptive requirement on believing what our beliefs entail:

(NR2) For any $\mathrm{P}$, one ought to believe that $\mathrm{Q}$ if one believes that $\mathrm{Q}$ is entailed by $P$.

For instance, Frank Jackson says:

'Someone who believes that $\mathrm{P}$, and that if $\mathrm{P}$ then $\mathrm{Q}$, ought to believe that Q. It is not simply that, by and large, they do believe that Q. It is that if they don't, there is something wrong.' (Jackson 2000: 101)

\footnotetext{
${ }^{1}$ For an analysis of the ambiguities in James's article between values and duties, and between epistemic and moral obligations, see in particular Haack 1997.
} 
Now, what is the relationship between the truth norm (NT) and the rationality norm (NR)? On the one hand, it is certainly a requirement that our beliefs are rational, but being a rational believer who has false beliefs is not a very desirable situation. On the other hand having true beliefs but being unable to see their rational connexions is not very desirable either. So the two norms seem to function together and to be on a par. But what exactly are their relations? Nick Zangwill (2005) has an interesting way of characterising the difference. He calls norms like (NT) 'vertical requirements,' about links between beliefs and the world, and norms like (NR) 'horizontal requirements,' about links between beliefs and beliefs or between beliefs and other mental states.

Now this distinction is related to another. Glüer and Wikforss (to appear) are concerned to discuss 'normativism,' the view according to which norms are in some sense essential or constitutive of contents. They distinguish two senses in which content can be said to be 'normative:' a) the sense in which the norms of thinking in general determine the normative character of the content or our beliefs (and of other mental states), which they call 'content determining normativism' $\mathrm{CD}$, and b) the sense in which the norms associated to the concepts which feature in the content which engender the norms 'content engendered normativism,' CE). In the first sense the norms come, so to say, from outside contents because they belong to the attitudes (here belief), whereas in the second sense, the norms so to say, come from within the contents, together with the concepts which figure in them (if 'meaning is normative,' presumably this is true for every word or concept). CE normativism is the view most commonly attached to Kripke and to the writers who claim that the normative dimension of contents come from the meaning or concepts and from the inferential role associated to them. CD normativism is the view that the norms are associated not to concepts but to the attitudes and mental states. ${ }^{2}$

My objective here is not to deal with the problem of the "normativity of content' as such. ${ }^{3}$ I am concerned with the normativity of belief as

\footnotetext{
${ }^{2}$ A related distinction is Bilgrami's (1992), between 'high profile' norms of rationality and 'low profile' norms attached to particular concepts and meaning.

${ }^{3}$ See among many others, Gibbard, Engel 2000, Boghossian 2003, Glüer 2000, Wikforss 2001.
} 
an attitude, and therefore with the claims of CD normativism, but my purpose is not to claim that mental content is normative, or in what sense it is, although this issue is obviously orthogonal to the present one, which is to investigate in what sense a norm of belief can be said to govern this mental attitude. Although Glüer and Wikforss' distinction between CD normativism and CE normativism is useful, I am not sure that it is always relevant to characterise normativist theses. It is relevant if we construe meanings and concepts as inferential roles independently from the truth conditions, as in views which like Brandom's (1994) characterise inferential role in terms of assertion conditions and rational relations. But it is irrelevant for those normativist theories of concepts which, like Peacocke's $(1992,2004)$ do not divorce inferential role from truth conditions, and insist that truth-links are as important as inferential links. In this sense it is not clear that rational requirements are independent from truth requirements. ${ }^{4}$

Similar questions arise about the relationship between the truth norm (NT) and evidential norms. It is often said that belief is subject to a norm of evidence, as well as to a norm of truth:

(NE) A belief is correct iff it is based on appropriate evidence.

There are, however, several concepts of evidence. If we associate evidence to subjective probability, and adopt the Bayesian concept of evidence, we shall have a fairly different concept from the one that we have if we characterise beliefs as governed by a norm of truth. Presumably (NT) goes with a categorical notion of belief as full belief, whereas the Bayesian notion goes with a notion of degree of belief determined by subjective probability. The relations between the two are notoriously problematic, and this problems transfers to the relations between NT and NE.

I shall also make three questionable assumptions. First, I shall abstract from the problem of what we may call the location of norma-

\footnotetext{
${ }^{4}$ Another reason why the question whether it is belief as an attitude or the concepts within belief contents which carry the normative load may not be two different questions is that when we attribute belief to ourselves and others, we use the concept of belief. Is ' $\mathrm{S}$ believes that P' normative because the concept of belief figures in this attribution (CD normativism) or because the attitude of belief is normative (CE normativism)? Both, presumably. That ascriptions of content are, according to normativism, normative, is used by Steglich-Petersen (to appear) as an argument against 'normative essentialism.'
} 
tive content - is it a property of belief or a property of the concepts which figure in beliefs? - and I shall assume that the norm for belief is attached to belief. Second I shall suppose that there is only one main norm for belief - the truth norm - and that the other norms are in some sense derivative from it. And third, I shall not try to assess the relationships between the norm of truth and these other derived or associated norms. ${ }^{5}$ Each of these assumptions may be questioned, but they are independent from the kind of question that I want to raise: supposing that truth is the fundamental norm for belief in what sense can we say that it is normative at all? This question has been the focus of many objections, and it these that I want to address.

So, I shall suppose that the main norm for belief is (NT). The problem I want to address here is this: is this formulation the right one? What are the conditions for its being right? Should we revise it in the face of the objections addressed to it? The main objection which is addressed against the truth norm is the following: in what sense is NT supposed to be genuinely normative, i.e. to regulate and to give us any guidance for our beliefs? If NT does not regulate belief at all, it is reduced to an abstract and empty requirement. In other words in so far as NT is supposed to cash out the intuition that 'beliefs aim at truth' there is just no such aim or norm for believers, for beliefs do not have any such target (many beliefs are not formed through a concern for truth), and it is completely idealistic to claim that believers could consciously entertain NT when they believe something.

\section{The objection from normative force}

The first objection which is addressed to NT is that it lacks normative force. Certainly, the objection goes, NT expresses a general requirement on belief. It is a basic condition on rationality that one's beliefs are true, but this condition merely tells us what our beliefs are and it gives us no directive about what we should do with our beliefs. Indeed, our beliefs aim at truth, and are supposed to be true if we are believers at all, but we have no choice. For there to be a norm, however, there has to be a must, a normative force, but also a normative freedom: the norm can be violated. But understood as a require-

\footnotetext{
${ }^{5}$ Elsewhere (Engel 2005) I have argued that the norm of truth is actually closely associated to the norm of knowledge, and derivative from it.
} 
ment on belief NT cannot be violated. As Kevin Mulligan (1999) has reminded us, a norm, to be a norm but be such that it can be broken and such that the person who breaks it can be criticised or sanctioned. And as Peter Railton (1999) reminds us, the normative force or the authority of a norm or normative principle (which is supposed to constrain us) goes hand in hand with normative freedom (our freedom to break the rules). Now, the objection goes, if a norm is merely a general rational principle, such as (NT) or (NR), it only says what a belief is (perhaps for an ideal rational agent), but it has no normative force. The point is well expressed by Glüer and Wikforss:

'The point can be put in terms of the notion of internal relations. The idea is that beliefs stand in basic internal relations to one another, such that being a believer in the first place requires that certain general patterns of very basic rationality are instantiated between those beliefs one has. Otherwise, it becomes unclear what the very content of those beliefs are, i.e. which beliefs it is that one has. This, also, makes it perfectly clear how beliefs differ from other cognitive attitudes, such as imaginings: Beliefs stand in various internal relations that imaginings do not. If I believe that $p$ and that if $p$ then $q$, I have a decisive reason to believe that $q$, whereas imagining that $p$ gives me no such reason.

However, to say that beliefs stand in various internal connections to one another is not to say that these connections are normative. On the contrary, precisely because the connections are internal or analytically necessary, they are not normative, not optional. If the connection were merely normative, it would be possible to violate the norm in question. That is, it would be possible to be in the one state without being in the other. This is precisely what is impossible if a relation between the states is internal. If the relation is internal, there is, so to speak, not enough room for any norm to enter between the two states. Of course, even if I (fully) believe that $p$ and that if $p$, then $q$, I can fail to draw the conclusion.' (Glüer and Wikforss, to appear)

A good example of a theory of rational norms which is not normative is Davidson's. Davidson talks a lot about the 'norms of rationality' which an interpreter of language and mind is bound to use, and takes these norms to be intrinsic to what meanings and mental contents are. But, to use his own metaphor, these norms are principles for 'measuring the mind' analogous to principles for measuring weight or temperatures. There are merely descriptive and offer us no guidance 
at all. Timothy Schroeder (2003; see also Glüer 2001, Engel to appear) distinguishes in this sense two notions of 'norm:'

a) As categorisation or classification schemes, in the sense of general idealised principles of description;

b) As force makers, that is as prescriptions or governance principles giving us aims to follow.

According to Schroeder, a theory of mind or a theory of content is fully normative only if it has norms in both senses a) and b). Otherwise, it is not normative, or is 'normative' only by courtesy. The normative force of a norm is this feature of it, which is such that it is susceptible to motivate us in doing what the norm prescribes, or, as Schroeder says, to have some sort of normative 'oomph.' As Schroeder rightly points out, Davidson's theory of mind is 'normative' only in the first sense, and not in the second sense. Hence, it is not 'normative:'

'His interest in rationality is thus an interest in it only insofar as it picks out a certain set of propositional attitude clusters (those which it would be fairly rational to hold) and distinguishes them from a different set of propositional — attitude clusters (those which it would be wildly irrational to hold). The fact that the patterns exhibited by the propositional attitudes of a rational organism are normatively commanded — that there exists a force-maker for the patterns — is of no significance in Davidson's theory.' (Schroeder 2003)

Schroeder's diagnosis seems to me perfectly right, and his confirmed by Davidson's answer to those who, like me, hold that there is a norm of truth for beliefs:

'When we say we want our beliefs to be true, we could as well say we want to be certain that they are, that the evidence for them is overwhelming, that all subsequent (observed) events will bear them out, that everyone will come to agree with us. It makes no sense to ask for more. But I do not think it adds anything to say that truth is a goal, of science or anything else. We do not aim at truth but at honest justification. Truth is not, in my opinion, a norm.' (Davidson 1998, in reply to Engel 1998)

The objection from normative force therefore says that if all there is to the norm of truth for belief that a belief is correct if and only if it is true, this 'norm' is no norm at all, and his perfectly trivial or shallow. 
What can we answer to this objection? There is something correct in it, which is that a mere categorisation scheme cannot be a norm, unless it is susceptible to have a normative force (I shall below have to qualify this). And for the norm to have force, we must be able to see in some way how it can guide our conduct, or, to use Shah's and Velleman's phrase (2005) to regulate, our conduct or our mental states.

Where, however, the objection goes wrong, is that from the fact that a norm is a categorisation scheme, it concludes that it cannot have normative force. But there is no reason why we should not distinguish two levels:

(a) The statement of the norm (the kind of analytic or constitutive or essential truth about belief it expresses);

(b) How the norm is regulated (its regulation).

It is one thing to say what the norm is, that is what kind of truth (analytic, or essential) is expressed by it, and it is another thing to say how the norm is regulated, and realised in the psychology of the believers. In this sense, (NT) expresses a basic truth, perhaps conceptual, perhaps essential (depending upon the kind of ontological status one grants to normative judgments or principles). ${ }^{6}$ But the question of how the norm is regulated is another matter. In particular, we cannot simply read off the regulation from the basic truth. And the fact that we simply state the rational or normative principle (NT) does not imply that the agent is necessarily motivated by the norm (a point familiar from Lewis Carroll's story of Achilles and the Tortoise). ${ }^{7}$ The distinction between the statement of the norm and the conditions of its regulation is reminiscent of the distinction between the formulation of a general norm on the one hand, and its conditions of application, or between the law and its decrees of application. ${ }^{8}$

\footnotetext{
${ }^{6}$ I said above that I would not deal with these ontological issues. One can be a conceptualist about the norms (it is a feature of our concepts), an expressivist (it is a feature of our psychological attitudes) or a realist-cognitivist (it expresses a real essence). See Wedgwood 2006, Zangwill 2005. Although I do not need to enter into these ontological issues, I believe, like Wedgwood, that the proper defence of the normative account needs a form of cognitivism.

${ }^{7}$ See Engel 2005, 2007 on Carroll's paradox.

${ }^{8}$ Several people have pointed out to me that the distinction is reminiscent of the distinction in moral theory of the general principle of utilitarianim and the particu-
} 
So in a sense, I grant the objection from normative force. Simply stating a rational principle like NT does not tell us how it is implemented in a believer's psychology. Still, it would be wrong to say that there is simply no relation between the principle and the regulation. There must be some relation between the principle and the regulation. Although the normative truth is necessarily independent from the way it is regulated, there has to be a connection between the two. What kind of connexion? In the first place it must be the case that the agent who violates the norm can be criticised for doing so. 'Criticised' does not necessarily mean: sanctioned or castigated. If I violate the norm that my beliefs be true, by entertaining false beliefs, I am not going to be beaten with sticks. But someone can certainly criticise me for having held false beliefs, and if I myself realise this, I ought, normally to change my beliefs. I shall say more on this in section 5 below, but in this respect it is not right to say that NT is such that it cannot be violated, since it applies to rational agents and that they cannot fail to conform to the norm. In the second place, the norm as an analytic or essential truth must be such that it can be obeyed. In other words, it must be such that the ought that it contains must imply can. I can be under no obligation to conform to a norm to which no human being can conform. And this condition on norms is the one which prompts the other set of objections against (NT).

\section{The objection from 'ought' implies 'can'}

According to this objection, the norm for belief is impossible to satisfy, because it imposes to believers constraints which are impossible to satisfy. It is not clear, however, that such an objection is always correct, for the fact that an agent cannot perform the action which a norm prescribes does not imply that he is not under the obligation to perform the action. In other words it is not clear that the 'ought implies can' principle is always correct. ${ }^{9}$ Let us come back to our initial formulation:

(NT2) For any P, one ought to believe that P iff P.

lar rules by which it is implemented (thanks to Tom Stoneham and Klemens Kappel for this).

${ }^{9}$ For objections, see for instance Stocker 1990, Ogien 2003. 
It is more complex that this statement seems to say. In the first place, John Broome has attracted our attention to differences of scope for what he calls 'normative requirements' (Broome 1999). (NT) can be read with a narrow or with a wide scope.

On the narrow reading, it says:

(NT2a) For any $S, \mathrm{P}: S$ ought to (believe that $\mathrm{P}$ ) if and only if $\mathrm{P}$ is true.

On the wide reading, it says:

(NT 2b) For any $S, P: S$ ought to (believe that $\mathrm{P}$ if and only if $\mathrm{P}$ is true).

The difference might not be apparent at this stage, but at first sight, the narrow scope reading seems to be the most natural one: the left hand side of the biconditional tells us what condition we must respect if we believe that $\mathrm{P}$ : to believe it iff it is true. The wide reading on the other hand tells us that we have to obey the whole biconditional (believe that $\mathrm{P}$ iff it is true). So let us, for the moment examine the narrow scope reading.

The narrow scope reading can itself be broken into two conditionals depending upon whether one reads it from right to left or left to right:

(NT2a*) For any $\mathrm{P}$, if $\mathrm{P}$ is true then $\mathrm{S}$ ought to believe that $\mathrm{P}$.

(NT2a**) For any $\mathrm{P}, \mathrm{S}$ ought to believe that $\mathrm{P}$ only if $\mathrm{P}$.

Suppose we interpret (NT2) through the first reading (NT2a*). A common objection to it (Haack 1997, Engel 2002, Boghossian 2003, Sosa 2008) is that on such a reading the norm is unsatisfiable or useless. Unsatisfiable: there are infinitely many truths, and by logic infinitely many truths equivalent to a given truth, which not only no one cares to believe, but also that no one could possibly believe.

(NT2a*) is also unsuitable as a norm for belief because there are plenty of trivial or uninteresting beliefs that are true, but that no one would, at least in usual circumstances, care to believe. For instance, that there are presently 36547 blades of grass on this corner of my garden is not something which I care to believe, although I could do so, if I cared to gather this truth. So it is not true, says the objection, that we have to believe any truth whatsoever. So (NT2a*) violates the ought implies can constraint or it is useless. 
For this reason a number of writers prefer the (N2a**) formulation (Boghossian 2003):

(NT 2a**) For any $\mathrm{P}, \mathrm{S}$ ought to believe that $\mathrm{P}$ only if $\mathrm{P}$.

or

(NT 2a***) For any $\mathrm{P}$, if $\mathrm{S}$ ought to believe that $\mathrm{P}$, then $\mathrm{P}$ is true.

Now, Bykvist and Hattiangadi 2007 have argued that it is not clear it works either.

(NT2a**), according to them, it 'does not capture the thought that the truth is what you ought to believe, since $\left(2 \mathrm{a}^{* *}\right)$ is not normative in any interesting sense - it does not imply that a subject is under any obligation under any circumstances whatsoever.' Bykvist and Hattiangadi write:

'Obviously, if $p$ is true, nothing whatsoever follows from (NT 2a**) about what $S$ ought to believe. Less obviously perhaps, if $p$ is false, nothing whatsoever follows about what $S$ ought to believe. For, if $p$ is false, it only follows that it is not the case that $S$ ought to believe that $p$. It does not follow, from the falsity of $p$, that $S$ ought not to believe that $p$. There is an important difference between 'it is not the case that $S$ ought to believe that $p$ ' and ' $S$ ought not to believe that $p$ ' — the former states that $S$ lacks an obligation to believe that $p$ and the latter states that $S$ has an obligation not to believe that $p$. The former is compatible with it being permissible for $S$ to believe that $p$, while the latter is incompatible with its being permissible for $S$ to believe that $p$. Hence, whether $p$ is true or false, (NT2a**) does not tell $S$ what to believe.' (Bykvist and Hattiangadi 2007)

Now, this objection has force only if the proposition $p$ is true or false independently of what the thinker takes it to be. In other words (NT2a**) makes sense when the think considers the proposition $p$, and asks himself whether it is true. I agree with Bykvist and Hattiangadi that nothing follows from (NT2a**) when the agent is not aware in any sense of the proposition. And actually they report the suggestion by Wedgwood that (NT2A**) that we should replace it by:

(NT 3) For any $S$, P: if $S$ considers whether $P$, then $S$ ought to (believe that $\mathrm{P})$ if and only if $\mathrm{P}$ is true. 
To this Bykvist and Hattiangadi point out that there are some sentences which act as what Sorensen (1988) calls 'blindspots,' i.e. as truths such as when we consider them we cannot satisfy the requirement of believing them, such as:

It is raining and nobody believes that it is raining;

There are no believers.

They remark that we could reformulate the condition (NT2a*) such that it is restricted only to believable truths:

(NT3a) For any $S$, P: if $S$ considers whether P, and P is truly believable, then $S$ ought to (believe that $\mathrm{P}$ ) if and only if $\mathrm{P}$ is true.

But then this seems to trivialise the requirement, and to say only: if $\mathrm{P}$ is true and believable you ought to believe that $\mathrm{P}$.

I do not find this objection to (NT3) very convincing. For certainly a requirement on $\mathrm{P}$ in (NT3) is that $\mathrm{S}$ actually understands $\mathrm{P}$, and it is not clear that the blindspot sentences in question can be understood. Moreover, the question of their truth can arise. And in so far that it can arise, the norm is in place. I shall come back below to the sense of (NT3) for the regulation of truth.

Now what about the wide scope reading of (NT2)? Remember that it says:

(NT2b) For any $S, P: S$ ought to (believe that $P$ if and only if $P$ is true).

As Bykvist and Hattiangadi comment, (NT2b) tells you that there are two combinations that will satisfy the requirement: either you believe that $p$ and $p$ is true, or it is not the case that you believe that $p$ and $p$ is false. At the same time, it tells you that there are two combinations that you ought to avoid: either you believe that $p$ and $p$ is false, or it is not the case that you believe that $p$ and $p$ is true.

The advantage of (NT2b) is that it is not clearly objectionable as (NT2a) is. For, (NT2b) cannot be broken down into the conditionals (NT2a*) and (NT2a**), for in those conditionals, the 'ought' took narrow scope. But now the problem, raised by John Broome about wide scope rationality requirements or norms is that we can't detach.

(NT2b) does not capture the intuition that the truth is what one ought to believe, or that a false belief is faulty or defective. Broome 
remarks that when we have a wide scope formulation of a modus ponens kind of argument of the form:

You ought (if you believe that $p$ and believe that $p$ implies $q$, believe that $q$ ); And that you believe the antecedent of what is in the scope of the 'ought'; You believe that $p$ and believe that $p$ implies $q$.

The inference to

You ought to believe that $q$.

does not go through.

Transposing now to the (NT2b) case, the same non detachment phenomenon appears. As Bykvist and Hattiangadi say, 'The reason is that what (NT2b) enjoins are combinations: the combination of your believing that $p$ with its being true that $p$ and the combination of its being false that $p$ and your not believing that $p$. Because the 'ought' takes wide scope, one cannot detach from (NT2b) that you ought to believe that $p$, even when $p$ is true.'

I agree with them that this is makes (NT2b) unsuitable for being the norm for belief. ${ }^{10}$ But the narrow scope reading and NT2a** stands.

\section{Truth and epistemic interests}

A third objection raised against NT is that it does not capture our interest for truth Piller (2006) argues that what he calls the 'standard view' (NT) is wrong if we formulate it in desire terms:

(DES) We desire that we believe that $\mathrm{P}$ iff $\mathrm{P}$ is true.

or:

DES $(\mathrm{BP} \leftrightarrow \mathrm{P})$

This, like (NT2), can be decomposed into two conditionals:

${ }^{10}$ Some writers, in particular Kolodny 2005, have accepted wide scope requirements on rationality. 
(i) $\quad$ DES $(\mathrm{P} \rightarrow \mathrm{BP})$

(ii) $\quad \mathrm{DES}(\mathrm{BP} \rightarrow \mathrm{P})$

Now Piller claims that (ii), which is the counterpart of (NT2A**) in desire terms, is implausible, because we can derive from it the implausible consequence that if someone believes that $\mathrm{P}$, he desires that $\mathrm{P}$, through the plausible 'transition principle' that if someone desires that if $\mathrm{A}$ then $\mathrm{B}$, and that $\mathrm{A}$ is the case, then she is rationally required to desire that $\mathrm{B}$.

$(\operatorname{Des}(\mathrm{A} \rightarrow \mathrm{B}) \& \mathrm{~A} \rightarrow$ Des $\mathrm{B})$.

To take one of Piller's examples: I want that if Jim does not get the post, then John should, and I hear that the appointment committee has already eliminated Jim, it follows that I hope that John will get it. Applying this to (ii) we get:

(1) Des $(\mathrm{B} P \rightarrow \mathrm{P})$ [ii]

(2) Des $(A \rightarrow B) \& A \rightarrow$ Des B [transition principle]

(3) Bel P $\rightarrow$ Des P

and (3) is certainly absurd: wanting that if A then B and noticing B certain does not commit me to want B.

As Kappel (to appear) has remarked, however, it is not clear that the desire formulation leads us to such paradoxical claims. If we contrapose we get the following from (1):

(4) Des (not-P $\rightarrow$ not B p).

And from this we may plausibly infer (with the help of (2)):

(5) not-P $\rightarrow$ Des (not Bel P).

which makes sense of something similar to what (NT2A*) expresses: we desire to avoid error, i.e., not to believe that $\mathrm{P}$ if $\mathrm{P}$ is false.

Even if we can agree with Piller that the desire formulation of (NT) is problematic, all it shows is that the proper formulation of (NT) may not be one in terms of desires like (DES), but the normative one. I quite agree with Clemens Kappel that: 
'The general lesson to be learned from this is that it is a mistake to try to capture our epistemic interests and commitments in terms of desires. There are senses in which if $\mathrm{P}$, you ought to believe that $\mathrm{p}$, and senses in which, if you believe $\mathrm{P}$, then $\mathrm{P}$ should be true, but neither are captured in terms of ordinary desires' (Kappel, to appear).

Piller claims that NT in its standard formulation implies that we want 'the truth and nothing but the truth.' He points out in his account of our interest in truth that this interest is not pure, and can coexist, or can be overridden, by our interests. This is similar to a common objection against taking truth as a goal of inquiry: we transform truth into a goddess. But there is no need to defend this sort of view to have norm of truth like (NT). The fact that our beliefs have side effects, or that we might want to believe certain things does not in any way abolish the distinction between our reasons for belief (our epistemic reasons) and our reasons for wanting to believe (which have nothing to do with an interest for truth). This is what the norm of truth is about. The norm of truth is not a truth goal, reflecting our interests and our desires. It is wrong to interpret the claim that one ought to have true beliefs and avoid having false beliefs as saying that we have a concern for truth for truth's sake. On the contrary, this claim is a claim about the regulation of our beliefs, and about their minimal epistemic regulation. This is what the last section is about.

\section{Truth and the regulation of belief}

The specificity of the regulation problem has been well isolated by Railton (1994) Velleman (2000) and Shah (2003): if a norm of truth for correct belief is in place, how can it actually guide our believings, without being either idle or the expression of a requirement too strong to be followed by any human agent?

As it has been suggested above about (NT3), NT makes most sense when a subject is considering her beliefs and asks herself the question 'do I believe that P?' in the context of a deliberation about her beliefs. There are, however, two ways of understanding this.

The first one is the intentional or teleological account, which takes seriously the metaphor the 'belief aims at truth:' to believe that $\mathrm{P}$ is to have the conscious aim of regarding $\mathrm{P}$ as true if and only if it is true. On this view, the regulation of NT is done through a conscious, intentional mental act of the believer. Velleman (2000) who proposes 
this account, allows that the teleological aiming at truth can be accounted, for those of our beliefs which are not conscious or explicit, by a teleological mechanism embedded in the believer's cognitive system. But even in this hypothesis believing is a matter of having a certain goal.

The main objections for the teleological account are these (Shah 2003, Engel 2005a). In the first place the teleological account fits only those beliefs which are consciously entertained and reflexive, and does not account for those which are not directed at truth, but at other aims, such as comforting the believer (e.g. cognitive dissonance, wishful thinking and all such 'irrational' believings. Even if we consider the non conscious beliefs, there is no reason to suppose that they are governed by a truth aim. In the second place, the teleological account represents believing as directed — consciously or not towards a goal, truth. But we have seen that this idea, which goes along with the analysis of the norm of truth in terms of desire, misrepresents the regulation of belief. It is not at all clear that belief has an aim in the sense in which stamp collecting or any other intentional activity has one (Owens 2003). As a result of these tensions, the teleological account is caught into what Shah (2003) calls the 'teleological dilemma:'

'one horn, the teleologist must allow the disposition that constitutes aiming at truth to be so weak as to allow paradigm cases in which beliefs are caused by such non-evidential processes as wishful thinking, in which case he cannot capture the exclusive role of evidence in one particular type of belief-forming process, reasoning. On the other horn, in order to account for the exclusive role of evidence in reasoning about what to believe, the teleologist must strengthen the disposition that constitutes aiming at truth so that it excludes the influence of non-truth-regarding considerations from such reasoning. However, by strengthening the truth-aimed disposition, the teleologist cannot accommodate the cases of wishful thinking, in which non-evidential factors clearly exercise influence over belief.' ( Shah 2003: 461)

Instead of the teleological account, Shah and Velleman have proposed what they call the transparency account, which analyses the process of 'doxastic deliberation' not in terms of an intentional mental act, but in terms of a simple recognition of the truth of the belief.

Transparency (Evans 1982, Moran 2001) is a phenomenon occurring in such processes, namely, the fact that whenever one asks one- 
self whether to believe that $p$, one must immediately recognize that this question is settled by, and only by, answering the seemingly different question whether $p$ is true. When our beliefs are in this sense transparent, i.e., to paraphrase Gareth Evans, when we direct our minds not to her beliefs, but to the world itself, no intentional aim is present. We recognise directly that we have the beliefs by considering their truth. The step is immediate and not inferential.

The transparency account allows us to understand how a normative truth about belief, to the effect that believing $p$ is correct if and only if $p$ is true, can explain transparency in doxastic deliberation. For in asking oneself whether to believe that $p$, one applies the concept of belief. If NT is a conceptual truth about belief, then it is a constitutive feature of the concept of belief that the correctness of believing $p$ is settled by settling the question whether $p$ is true. So applying the concept of belief in forming a belief thus involves applying the correctness norm to one's own belief-formation.

The transparency account also explains the difference between reasons to believe and reasons for wanting to believe. One can want to believe that $\mathrm{P}$ without considering (indeed trying to bracket) whether $\mathrm{P}$ is true, but one cannot believe that $\mathrm{P}$ in the deliberative sense of considering whether $\mathrm{P}$ without asking oneself whether $\mathrm{P}$ is true.

The transparency account, however, seems to imply that

'the motivation stemming from the thought that true beliefs are correct has to be so strong, if it is to do the desired explanatory work, that it is implausible to regard it as motivation stemming from acceptance of a norm at all' (Steglich Petersen 2006).

The point is that the relation between the norm and its regulation becomes now so intrinsic that it cannot be normative: a norm which necessarily motivates does not motivate at all. This objection is very similar to the one from normative force above. As Steglish Petersen says:

'If transparency is produced by the norm of belief, this norm motivates one necessarily and inescapably to act in accordance with it. The transparency is immediate, and does not involve an intermediary question about whether to conform to the norm for belief; the norm is thus unlike norms such as the one governing promising. It is thus doubtful whether a consideration which necessitates motivation should be considered a normative consideration at all.' 
I do not see, however, why the internal relationship between the norm and its regulation which the transparency account introduces implies that the norm necessarily motivates us. It does not motivate in the many cases where we are not self conscious in this way, and many cases where we simply disregard the norm. Just as cases of akrasia or accedia can arise where the agent considers the norm but does not follow it, cases where the norm of truth is considered by the agent but is not followed can arise. One could analyse self deception along these lines. In this respect we can break the norm, or fail to conform to it. Does it motivate us in the conscious case? Steglish-Petersen objects that in this case too the transparency account implies that we are necessarily motivated. But I do not see why the norm, as I understand it here, necessarily motivates us. As I understand it, the norm is a constitutive principle implicit in our understanding of what a belief is. This principle may not be always present to our mind, and even when it is present, we need not follow it ( I grant that there can be 'epistemic akrasia' and other such internal inconsistencies within a subject ${ }^{11}$ ). So it is not clear that there is any necessary connexion between the expression of the norm as a constitutive feature of belief, and its regulation.

The transparency account of NT that it applies both to the cases of conscious deliberations about beliefs. and to non conscious cases. We can associate the normative account of belief to a set of rational dispositions of the believer, which can, in a number of cases, fail to be triggered (Wedgwood 2007).

The transparency account of truth regulation allows us also to answer an objection formulated by Glüer and Wikforss Seeing correctly the difference between the objective norm for belief (NT) and the way it regulates our believing through subjective norms, they write:

'The question is how such norms [subjective] guide our actions. Being guided by a norm such as 'buy low and sell high' requires having some beliefs about the market. For instance, if I believe that the market is at a low (and I intend to follow this rule plus have the required background beliefs and desires) I will buy. However, applying this to N1 [ NT2a*] we get: If you hold $p$ true, then you ought to hold $p$ true. It is rather obvious that no guidance can be had from this. The trouble with N1, there-

\footnotetext{
${ }^{11}$ I have defended this view in 'Akrasia Pratique et Akrasia Épistémique,' Le Philosophoire 19, 'L'Action,' 2007.
} 
fore, is not that it is an objective norm, but that it cannot guide our belief formation and hence is not a norm for belief.'

The point is that the prescription 'Believe that $\mathrm{P}$ only $\mathrm{P}$ is true' is void, since in order to obey it, one must already believe P. This objection would make sense if the correctness condition for belief were a prescription such that, in order to obey it, a precondition ( to believe that P) had to be satisfied. But if the regulative condition is conceived in the transparency sense, there is no circularity here: to ask oneself whether to believe that $\mathrm{P}$ and asking oneself whether $\mathrm{P}$ is correct are one and the same thing as asking oneself whether $\mathrm{P}$ is true. ${ }^{12}$

The transparency account of truth regulation allows us also to answer an objection formulated by Glüer and Wikforss seeing correctly the difference between the objective norm for belief (NT) and the way it regulates our believing through subjective norms, they write:

'The question is how such norms [subjective] guide our actions. Being guided by a norm such as 'buy low and sell high' requires having some beliefs about the market. For instance, if I believe that the market is at a low (and I intend to follow this rule plus have the required background beliefs and desires) I will buy. However, applying this to N1 [ NT2a*] we get: If you hold $p$ true, then you ought to hold $p$ true. It is rather obvious that no guidance can be had from this. The trouble with N1, therefore, is not that it is an objective norm, but that it cannot guide our belief formation and hence is not a norm for belief.'

The point is that the prescription 'Believe that $\mathrm{P}$ only if $\mathrm{P}$ is true' is void, since in order to obey it, one must already believe $\mathrm{P}$. This objection would make sense if the correctness condition for belief were a prescription such that, in order to obey it, a precondition (to believe that $\mathrm{P}$ ) had to be satisfied. But if the regulative condition is conceived in the transparency sense, there is no circularity here: to ask oneself

\footnotetext{
${ }^{12}$ Steglish-Petersen also objects to the transparency account of NT that it applies only to the cases of conscious deliberations about beliefs. But I do not see why it does not apply to other cases as well. We can associate the normative account of belief to a set of rational dispositions of the believer, which can, in a number of cases, fail to be triggered (Wedgwood 2007).
} 
whether to believe that $\mathrm{P}$ and asking oneself whether $\mathrm{P}$ is correct are one and the same thing as asking oneself whether $\mathrm{P}$ is true. ${ }^{13}$

\section{Conclusion}

I conclude, therefore, that, properly understood, through distinguishing the truth expressed by the norm for belief and its regulation, and by having a proper account of the regulation of belief, the normative account of the correctness condition for belief stands and that the objections from normative force and from the unsatisfiability of the norm can be answered. Many issues are still unsettled, such as the consequences that this conclusion has for the normativity of content in general, and for the ontology of norms. But I am confident that we can raise these issues, which are left open, by presupposing that the normative account is correct. ${ }^{14}$

Pascal Engel

Départment de Philosophie, Faculté des Lettres Université de Genéve 2, Rue de la Candolle (4e étage) CH 1211 Genéve, Switzerland Pascal.Engel@lettres.unige.ch

\section{References}

Bilgrami, A. 1992. Belief and Meaning. Oxford: Blackwell.

Boghossian, P. 2003. The normativity of content. Philosophical Issues 13: 31-45.

\footnotetext{
${ }^{13}$ Glüer and Wikforss write about Shah's transparency condition. Instead, Shah argues, we have to say that there is an internal relation between discovering that $p$ is true and believing that $p$, and this requires accepting that N1 is a condition of possessing the concept of belief. Shah is surely right that there is an internal relation here, one that does not depend on the aim of believing what is true. However, precisely because of this there is no room for a norm. Shah, it might be said, falls prey to the very same objection that he levels against Velleman: His account leaves open the possibility that one may discover that $p$ is true, without the question of whether to believe that $p$ being settled. But this objection can only be made if one understands the norm of truth as external to the activity of believing.

${ }^{14}$ I would like to thank, for their comments on this text and its previous versions: John Skorupski, Kathrin Glüer, Asa Wikforss, Asbjorn Steglich-Pedersen, Ralph Wedgwood, Kevin Mulligan, Julien Dutant, Anne Meylan, David Owens and Klemens Kappel.
} 
Brandom, R. 1994. Making it Explicit. Harvard: Harvard University Press. Broome, J. 1999. Normative Requirements. Ratio, repr. in Dancy 2000.

Bykvist, K. \& Hattiangadi, A. 2007. Does Thought Imply Ought? Analysis 67 (296): 277-285.

Dancy, J., ed. 2000. Normativity. Oxford: Blackwell.

Davidson, D. 1998. 'Reply to Pascal Engel,' in L. Hahn, ed. The Philosophy of Donald Davidson, 460-1.

Engel, P. 2000. Wherein lies the normative dimension in mental content? Philosophical Studies. 2000, 100, 3, 305-321

Engel, P. 2002. Truth Bucks: Acumen.

Engel, P. 2005. Truth and the aim of Belief, in D. Gillies, ed. Laws and Models in Science, London: King's College Publications, 79-99.

Engel, P. 2006. Epistemic norms and rationality,' in W. Strawinski, M. Grygianca, \& A. Brodek, eds., Mysli o Jezyku, nauce I wartosciach, Ksiega ofiarowana Jackowi Juliuzowi Jadakiemu, Warsawa: Semper, 355-370.

Engel, P. (to appear) Davidson on epistemic norms, in C. Amoretti \& N. Vassalo, Davidson: Language, Mind and Interpretation. Munich: Ontos Verlag.

Evans, G. 1982. The Varieties of Reference. Oxford: Oxford University Press.

Gibbard, A. 2003. Thoughts and Norms. Philosophical Issues 13: 83-98.

Glüer K, 2001. Dreams and Nightmares. Conventions, Norms, and Meaning in Davidson's Philosophy of Language, in Kotatko, P. Pagin, G. Segal, eds., 2001: 53-74.

Glüer, K \& Wikforss, A. (to appear) Against Content Normativity.

Haack S. 1997. The Ethics of Belief Reconsidered, in L. Hahn, The Philosophy of Roderick Chisholm. Open Court, La sale, Ill., repr. in Zagzebski and Fairweather 2000.

Heal, J. 1986. The disinterested Search for Truth. Proceedings of the Aristotelian Society 97-108.

Jackson, F. 2000. Cognitivism, Normativity, Belief, in Dancy 2000.

James, W. 1896. The Will to Believe, reed. New York Dover Books, 1956.

Kappel, K. (to appear) Comments on Piller.

Kolodny, N. 2005. Why be Rational? Mind 114:509-562.

Kotatko, P. Pagin, P. \& Segal, G., eds. 2001. Interpreting Davidson, Stanford: CSLI Publications.

Moran, R. 2001. Authority and Estrangement. Princeton: Princeton University Press.

Mulligan, K. 1999. Justification, Rule Breaking and the Mind. Proceedings of the Aristotelian Society 99 (2):123-139.

Ogien, R. 2003. Le rasoir de Kant. L'Eclat, Paris, Tel Haviv.

Owens, D. 2003 Does Belief Have an Aim? Philosophical Studies 115, No. 3.

Peacocke, C. 1992. A Study of Concepts. Cambridge, Mass: MIT Press. 
Piller, C. (to appear) Desiring the Truth and Nothing but the Truth, in A.Haddock, A. Millar and D. Pritchard, eds., Epistemic Value, Oxford: Oxford University Press.

Railton, P. 1994. Truth, Reason, and the Regulation of Belief, in Engel, P. 2000 ed. Believing and Accepting, Dordrecht, Kluwer repr in Railton 2003.

Railton, P. 1999 Normative Force and Normative Freedom, in Dancy 2000 and in his Rules, Values and Norms, Cambridge, Cambridge University Press, 2003: 179-208.

Schroeder, T. Davidson's Theory of Mind is Non Normative, Philosophers' Imprint 3 (1): 1-14.

Shah, N. 2003.How Truth Regulates Belief. Philosophical Review: 113.

Shah, N. and Velleman, D. 2005. Doxastic deliberation. Philosophical Review 114, 2: 497-534.

Sorensen, R. 1988. Blindspots. Oxford: Oxford University Press.

Sosa, E. 2007. A Virtue Epistemology, Oxford: Oxford University Press.

Steglich-Petersen, A. 2006. The Aim of Belief: no Norm Needed. The Philosophical Quarterly 56, 225: 500-516.

Stocker, M. 1990. Plural and Conflicting Values. Oxford: Oxford University Press.

Velleman, D. 2000. On the Aim of Belief, in his The Possibility of Practical Reason, Oxford: Oxford University Press.

Wedgwood, R. 2002. The Aim of Belief. Philosophical Perspectives 16: 276-297.

Wedgwood, R. 2007 Normativism Defended, in Cohen, J. and Mc Laughlin, J. eds. Contemporary Debates in Philosophy of Mind, Oxford: Blackwell.

Wedgwood, R. 2007. The Nature of Normativity. Oxford: Oxford University Press.

Wikforss, A. 2001. Semantic Normativity. Philosophical Studies 102: 203-226.

Zangwill, N. 2005. The Normativity of the Mental. Philosophical Explorations 8, 1, March: 1-19. 